\title{
EDUCAÇÃO AMBIENTAL EM MUSEUS E ACERVOS DE CIÊNCIAS NATURAIS
}

\author{
Graziella Plaça Orosco de Souza ${ }^{1}$ \\ Angelita de Almeida Oliveira Lima ${ }^{2}$ \\ Antonio Fluminhan Junior ${ }^{3}$
}

\begin{abstract}
RESUMO
O presente artigo descreve as estratégias adotadas por uma universidade para a constituição de um espaço destinado ao desenvolvimento de atividades relacionadas à Educação Ambiental. Foram utilizadas ações integrando coordenações de cursos, docentes, acadêmicos e funcionários, com o propósito de viabilizar a criação do Acervo Educacional de Ciências Naturais - AECIN da Universidade do Oeste Paulista - UNOESTE. Estudos para a implantação do AECIN foram iniciados a partir da demanda existente no Curso de Ciências Biológicas e, posteriormente, em outros cursos das Ciências Agrárias e Engenharias. Foi utilizada uma abordagem metodológica qualitativa como norteadora do levantamento de estratégias para a Educação Ambiental nas esferas mundial e nacional. Em adição, foi realizada uma análise documental visando ao entendimento das metodologias usualmente empregadas para a Educação Ambiental em museus e acervos de Ciências Naturais. Também foram realizadas pesquisas através de questionários aplicados aos visitantes de suas coleções, e que constituem o banco de dados do AECIN. Constata-se que o AECIN representa uma importante iniciativa de Educação Ambiental, uma vez que beneficia públicos variados de diversos municípios da região Oeste Paulista e, em especial, crianças e jovens matriculados desde o ensino fundamental ao superior. Além disto, o AECIN promove ações de ensino, pesquisa e extensão, sendo que as visitas monitoradas à sua coleção permanente totalizaram 2.229 visitantes no período de 2008 a 2014. Neste mesmo período, um total de 14.607 visitantes foram recebidos pelas suas exposições itinerantes. Estes números expressam a relevância deste ambiente para o desenvolvimento de ações que favoreçam o ensino das questões ambientais a todos os níveis educacionais.
\end{abstract}

PALAVRAS-CHAVE: Educação Ambiental, Acervo Educacional de Ciências Naturais, Preservação Ambiental.

\section{ENVIRONMENTAL EDUCATION IN MUSEUMS AND COLLECTIONS OF NATURAL SCIENCES}

\footnotetext{
${ }_{1}^{1}$ Mestranda em Meio Ambiente e Desenvolvimento Regional, Universidade do Oeste Paulista. E-mail graza@unoeste.br.

Mestre em Educação, Pró-Reitora de Extensão e Ação Comunitária, Universidade do Oeste Paulista. E-mail: angelita@unoeste.br

3 Doutor em Genética e Fisiologia Celular, Docente do PPG em Meio Ambiente e Desenvolvimento Regional, Universidade do Oeste Paulista. E-mail: fluminhan@unoeste.br.
} 


\begin{abstract}
This article describes the strategies adopted by a university to create a space for the development of activities related to environmental education. Activities involved the integration of coordination of courses, teachers, academics and staff in order to enable the launching of the Educational Collection of Natural Sciences - AECIN by the University of Western São Paulo - UNOESTE. Studies for the implementation of AECIN started from the existing demand in the Biological Sciences course and later in other courses of Agricultural Sciences and Engineering. A qualitative methodological approach performed for the review of strategies for Environmental Education in global and national levels. In addition, a documentary analysis took place with the purpose of understanding the methodologies usually employed for Environmental Education in museums and collections of Natural Sciences. Surveys also conducted from questionnaires given to the visitors of AECIN collections, which constitute the AECIN database. It could be observed that the AECIN plays an important role for Environmental Education, since it benefits varied people from several municipalities of the Western São Paulo region and, in particular children and youth enrolled from primary school to university. In addition, the AECIN promotes educational, research and extension actions, and the guided visits to its permanent collection totaled 2,229 visitors from 2008 to 2014. In the same period, up to 14,607 visitors have been registered by its traveling exhibitions. These figures express the importance of this space for the development of actions that promote the teaching of environmental issues at all educational levels.
\end{abstract}

KEYWORDS: Environmental Education, Educational Collection of Natural Sciences, Environmental Preservation.

\title{
EDUCACIÓN AMBIENTAL EN MUSEOS Y COLECCIONES DE CIENCIAS NATURALES
}

RESUMEN

Este artículo describe las estrategias adoptadas por una universidad para formar un espacio para el desarrollo de actividades relacionadas con la Educación Ambiental. Las acciones incluyeron la integración de la coordinación de cursos, profesores, académicos y personal con el fin de permitir la creación de la Colección Educacional de las Ciencias Naturales - AECIN en la Universidad del Oeste Paulista - UNOESTE. Estudios para la implementación de AECIN se iniciaron a partir de la demanda existente en el Curso de Ciencias Biológicas y más tarde en otros cursos de Ciencias Agrícolas y Ingeniería. Se utilizó un enfoque metodológico cualitativo como orientar las buscas por estrategias para la Educación Ambiental en los niveles mundial y nacional. Además, se llevó a cabo el análisis documental dirigido a la comprensión de las metodologías empleadas habitualmente para la Educación Ambiental en museos y colecciones de Ciencias Naturales. También se llevaron a cabo las investigaciones a través de cuestionarios dados a los visitantes de sus colecciones, que constituyen la base de datos de AECIN. Parece ser que el AECIN es una iniciativa importante para la Educación Ambiental, ya que beneficia variado público de varios municipios de la región Oeste Paulista y en particular los niños y jóvenes matriculados en la escuela primaria hasta la universidad. Además, el AECIN promueve acciones educativas, de investigación y extensión, y las visitas guiadas a la colección permanente tiene totalizados 2.229 visitantes entre 2008 y 2014. En el mismo período, se recibieron un total de 14.607 visitantes por sus exposiciones itinerantes. Estas cifras expresan la importancia de este espacio para el desarrollo de acciones que promuevan la enseñanza de las cuestiones ambientales en todos los niveles educativos.

PALABRAS CLAVE: Educación Ambiental, Colección Educacional de las Ciencias Naturales, Conservación del Medio Ambiente. 


\section{INTRODUÇÃO}

A concepção do homem como ser superior a tudo o que o cerca, envolve uma questão ética nas relações sociais. Durante bastante tempo, o ser humano foi considerado superior ao restante dos seres vivos. Este fato pode ser explicado pelo relacionamento destrutivo que a humanidade mantém até hoje em relação à natureza, confirmado no sistema de produção, na educação, na cultura e até mesmo na religião ${ }^{1}$. A noção de "soberania existencial" é transmitida de geração a geração e confirmada diariamente nas relações sociais.

O conceito de Meio Ambiente Total, que envolve também o ser humano, se perdeu ao longo do processo evolutivo das organizações sociais, e esse conceito deixou de ter importância. A crise civilizatória em que o mundo atual vem passando traz à tona uma série de discussões que, por muito tempo, ficaram ocultas nas pautas sociopolíticas mundiais. Talvez, o mais visível desses conceitos seja o de desenvolvimento sustentável, que substituiu o conceito de desenvolvimento econômico, sempre tão almejado pelas nações em crescimento.

A Educação Ambiental pode contribuir muito para a sensibilização em relação à questão ambiental, uma vez que ela trata de questões sociais, políticas e econômicas, e busca contribuir para a formação de cidadãos socialmente e ecologicamente responsáveis.

Este trabalho se propõe a levantar as principais discussões sobre $o$ assunto "Educação Ambiental", bem como discutir o seu efetivo desenvolvimento no Brasil e o papel que os museus e acervos de Ciências Naturais podem desempenhar na contribuição para a propositura de estratégias metodológicas de sucesso. Além disso, este artigo apresenta a experiência de uma universidade em constituir um espaço visando ao desenvolvimento de práticas relacionadas à Educação Ambiental em vários níveis educacionais.

\footnotetext{
1 "No passado, estávamos a meio caminho entre os animais e Deus. Depois viramos filhos de Deus, feitos à Sua imagem e semelhança." (CORTELLA, Mário Sérgio; BARROS FILHO, Clóvis de. Ética e vergonha na cara! Campinas: Papirus, 2014, p. 46 - Col. Papirus Debates).
} 


\section{Breve histórico da Educação Ambiental}

O desenvolvimento sustentável foi, e ainda é, pauta de encontros e conferências locais e mundiais sobre a questão ambiental. A partir da década de 1960, o modelo produtivo e o consequente crescimento desenfreado das economias mundiais tornaram a inquietação em relação ao Meio Ambiente uma constante. Esta preocupação foi afirmada e divulgada na publicação intitulada "Limites do Crescimento", também conhecido como "Relatório Meadows" que acabou por tornarse o livro sobre a questão ambiental mais vendido na história.

Tal publicação foi impulsionada pelo Empresário italiano Aurelio Peccei, fundador da $\mathrm{FIAT}^{2}$, onde atuou como presidente por 20 anos. Peccei e o cientista escocês Alexander King fundaram, em abril de 1968, o Clube de Roma, que foi um grupo de empresários preocupados com a escassez de recursos naturais, que abalaria toda a estrutura de produção vigente naquele momento. "Limites do Crescimento" abordava problemas decisivos para o destino da humanidade (energia, poluição, saneamento, saúde, ambiente, tecnologia e crescimento populacional).

A partir de então, diversas foram as conferências mundiais e internacionais que trataram da questão ambiental sob diferentes aspectos, sendo a primeira delas realizada em 1972 em Estocolmo (Suécia). Promovida pela Organização das Nações Unidas - ONU, a Primeira Conferência Mundial de Meio Ambiente Humano trouxe uma discussão acerca da educação, afirmando que se deve educar o cidadão para a solução dos problemas ambientais. Pode-se considerar que foi neste encontro que surgiu o que se convencionou chamar de "educação ambiental".

Em 1975 ocorreu o Seminário Internacional de Educação Ambiental em Belgrado (lugoslávia), encontro organizado pela UNESCO, no qual foram formulados os princípios e as orientações para o Programa Internacional de Educação Ambiental - PIEA. O referido Programa formulou os seguintes princípios orientadores: a Educação Ambiental deve ser continuada, multidisciplinar, integrada

\footnotetext{
${ }^{2}$ FIAT (Fabbrica Italiana Automobili Torino) é um dos maiores fabricantes de automóveis do mundo, com sede mundial na cidade de Turim, norte da Itália. "Fiat" também pode significar "faça-se" em Latim.
} 


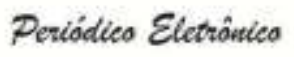

às diferenças regionais e voltada para os interesses nacionais. Algumas orientações para a Educação Ambiental encontram-se na Carta de Belgrado.

Dois anos depois, em 1977, foi realizado o Primeiro Congresso Internacional de Educação Ambiental da Unesco, em Tbilisi, Geórgia. Fortemente inspirado pela Carta de Belgrado, este encontro seria responsável pela elaboração de princípios, estratégias e ações orientadoras em Educação Ambiental, os quais são adotados até os dias atuais, em todo o mundo. Em 1987 foi realizado o Congresso Internacional da UNESCO - PNUMA sobre Educação e Formação Ambiental, em Moscou, União Soviética, que deu continuidade à discussão desta questão.

Entre os anos 1987/88, várias reuniões foram promovidas pela primeiraministra norueguesa Gro Harlem Brundtland, que resultaram na publicação do livro "Nosso Futuro Comum", também conhecido como Relatório Brundtland, que forneceu subsídio para as discussões da Conferência Rio 92. O Relatório reafirma a necessidade de se pensar em um desenvolvimento econômico e social que possa satisfazer as necessidades presentes, no entanto, sem comprometer, a capacidade das futuras gerações. A publicação ressalta os riscos do uso demasiado dos recursos naturais sem que se avalie a capacidade de suporte dos ecossistemas.

Em 1992 foi realizada a Conferência das Nações Unidas para o Meio Ambiente e Desenvolvimento - Rio 92, que também ficou conhecida por Eco 92. Realizada no Rio de Janeiro, Brasil, a conferência foi responsável pela inclusão do tema Meio Ambiente na agenda política planetária. A Eco 92 produziu documentos que norteiam ações de sustentáveis, sendo o mais conhecido a Agenda XXI. No Brasil, o documento enfoca os programas de inclusão social, tratando da importância de se garantir o acesso de toda a população à educação, saúde e distribuição de renda. Também estão presentes a questão da sustentabilidade urbana e rural, a preservação dos recursos naturais e minerais e a ética política para o planejamento rumo ao desenvolvimento sustentável. Este documento foi traduzido para diversos idiomas e reescrito para diferentes níveis educacionais, no intuito de facilitar a sua aplicação no interior das escolas de Ensino Básico.

No ano de 1997, ocorreu a Conferência Internacional da Unesco sobre Meio Ambiente e Sociedade: Educação e Consciência Pública para a Sustentabilidade, realizada em Thessaloniki, Grécia. Em sua Declaração, publicada em 1998, são 
reafirmados vários assuntos discutidos nas conferências anteriores, dentre eles o de que:

\begin{abstract}
A educação é um meio indispensável para propiciar, a todas as mulheres e homens do mundo, a capacidade de conduzirem suas próprias vidas, exercitarem a escolha e a responsabilidade pessoal e aprenderem através de uma vida sem restrições geográficas, políticas, culturais, religiosas, linguísticas ou de gênero (DECLARAÇÃO de Thessaloniki, 1998, p. 2).
\end{abstract}

Com relação à Educação Ambiental, a Declaração de Thessaloniki (DECLARAÇÃO de Thessaloniki, 1998, p. 2) menciona que:

\begin{abstract}
A educação ambiental, tal como desenvolvida no quadro das recomendações de Tbilisi e evoluída desde então, focando todo tipo de questões globais tratadas na Agenda 21 e nas grandes Conferências das Nações Unidas, também foi tratada como educação para a sustentabilidade. Isso permite a referência à educação para o meio ambiente e a sustentabilidade.
\end{abstract}

No ano de 2002, a Conferência das Nações Unidas para o Desenvolvimento Sustentável - Rio +10 , realizada em Johanesburgo, África do Sul, quase não menciona a questão da Educação Ambiental, voltando, no entanto, a debater a questão da necessidade de um desenvolvimento sustentável. A Rio+10 almejou buscar harmonia na avaliação das condições atuais e nas prioridades para ações futuras em termos ambientais, reforçando compromissos para favorecer com que os objetivos da Agenda 21 sejam alcançados.

Em 2012, realizou-se a Conferência das Nações Unidas sobre Desenvolvimento Sustentável, a Rio+20, no Rio de Janeiro, Brasil. A Rio+20 produziu vasta publicação, com destaque para o "Relatório Rio+20: o Modelo Brasileiro" e os "Cadernos de Sustentabilidade da Rio+20". Sendo considerada decepcionante para alguns e promotora de avanço nos acordos políticos para outros, a Rio+20 proporcionou a retomada do debate da Educação Ambiental em diversas esferas sociais e níveis educacionais, inclusive vinculada ao conceito de Cultura da Paz.

Por este exposto, verifica-se que a Educação Ambiental, amplamente discutida desde a década de 1960, por levantar questões de ordem social, questiona indiretamente o modo de visa da sociedade atual e sua relação com a natureza. No mundo todo, as nações se preocuparam em formalizar a questão em políticas 
públicas e a incluíram em sua agenda de governo.

\section{A Educação Ambiental no Brasil}

No Brasil, a Política Nacional de Meio Ambiente foi instituída pela Lei $\mathrm{n}^{\circ}$ 6.938, de 31/08/81. Em seu Art. $2^{\circ}$, inciso $X$, a referida Lei prevê a "Educação Ambiental a todos os níveis de ensino, inclusive a educação da comunidade, objetivando capacitá-la para participação ativa na defesa do meio ambiente" (BRASIL, 1981).

Apesar da publicação desta legislação nacional, a Educação Ambiental foi efetivamente iniciada no Ensino Básico apenas em 1995, com a publicação dos Parâmetros Curriculares Nacionais (PCNs) que passou a nortear os trabalhos metodológicos no interior das escolas, no que a questão ambiental passou a ser tratada como um dos temas transversais propostos. No entanto, esta estratégia favoreceu a desarticulação da Educação Ambiental do quadro curricular formal das escolas, como acontece com as demais disciplinas, favorecendo com que frequentemente se apresente trabalhada quase que exclusivamente no formato de atividades complementares e/ou datas comemorativas.

O resultado desta falta de integração entre os assuntos ambientais e o cotidiano escolar favorece uma visão desarticulada da relação entre ser humano e natureza. Somado a este fato, o contexto midiático atual que - a todo momento induz ao consumo excessivo e desnecessário, também se apropria do conceito de sustentabilidade para justificar a sobreposição do ser humano sobre a natureza por meio da utilização dos recursos naturais. Conceitos como sustentabilidade, desenvolvimento sustentável e economia verde precisam ser melhor trabalhados para que não se percam seus reais significados.

A Educação Ambiental pode atuar em prol da compreensão da relação ser humano/natureza, garantindo a formação com senso de responsabilidade e dever para com o Meio Ambiente. Para tanto, são necessárias novas metodologias que possam favorecer o processo de ressignificação de conceitos, promovendo o resgate do conceito de humanidade como parte da natureza, como parte desse Meio Ambiente Total. Conforme Waldman (2006, p. 124), 


\begin{abstract}
"sensibilidade ambiental" muitas vezes assim entendida pelo próprio imaginário ecologista. Outra completamente diferente é com isso pretender igualá-lo ao mundo ocidental. Nada mais falso e improcedente. Hoje, destrói-se o ambiente natural em escala e velocidade jamais vistas e, para completar, numa ferocidade igualmente jamais registrada nos tempos que nos precederam (...).
\end{abstract}

Para que esta ressignificação conceitual ocorra, não basta que os conteúdos curriculares sejam alterados. Torna-se necessária a efetiva mudança na organização escolar. Para que se garanta esta transformação, seria preciso primeiramente alterar a maneira como a escola se organiza e efetivamente funciona, aproximando-a da realidade da sociedade. Experiências bem sucedidas podem se tornar de exemplo para o pleno exercício da Educação Ambiental. Fatores enriquecedores de metodologias educacionais vêm sendo experimentados com bons resultados, como é o caso da Educação Ambiental em espaços não escolares, dentre estes, os museus e acervos de História Natural.

\title{
Educação Ambiental em museus e acervos de Ciências Naturais
}

Desde o surgimento das primeiras sociedades organizadas, o ser humano necessita transmitir conhecimentos aos seus descendentes. Por meio da linguagem, a memória oral foi transmitida de geração a geração como forma da garantia de sobrevivência em situações adversas e, em especial, para relatar experiências anteriores. Antes do surgimento da escrita, objetos como pedras, conchas, ossos, peles, dentes eram conservados, pois tinham significância histórica para a comunidade e para a transmissão desses conhecimentos.

Escavações arqueológicas permitiram descobrir que vários tipos de objetos eram colecionados pelas populações primitivas, e obedeciam a critérios segundo o entendimento da época. Estas descobertas traduzem o apego do ser humano aos bens materiais, fato que veio a ser solidificado e legitimado nos museus, acervos e centros de memória criados pelas diferentes sociedades organizadas do mundo, perdurando até os dias atuais. Com as grandes navegações e a descoberta de novos mundos, como o continente americano, com sua fauna e flora típicas, as pessoas passaram a ter uma noção mais ampla da diversidade biológica existente no planeta.

Assim, os museus e centros de estudos e pesquisas voltaram seus olhares 
para a importância da preservação de exemplares não só de cunho antropológico, mas também, criadas pela própria natureza. Surgiram assim as primeiras coleções ligadas às Ciências Naturais.

No Brasil, a primeira instituição dedicada à História Natural foi o Museu Nacional do Rio de Janeiro, criado em 1818, por D. João VI, e considerado o maior museu do gênero da América Latina. Atualmente, esta instituição encontra-se fechada à visitação em razão da falta de incentivo em recursos financeiros públicos sua para manutenção básica ${ }^{3}$.

Sabe-se que cerca de $60 \%$ dos Museus e Centros de Ciências existentes no Brasil pertencem a universidades (SANTOS, 2006). Os museus e acervos podem promover a compreensão pública da ciência por meio de experiências educativas informais ou não formais, e proporcionar a divulgação de informações científicas de forma agradável e em um ambiente diferenciado de ensino. No interior de uma coleção museológica, o patrimônio não se constitui em uma propriedade individual, mas sim um produto do coletivo, o resultado de um processo de desenvolvimento. Com o patrimônio ambiental não é diferente. A proteção do Meio Ambiente também é o processo de proteção do patrimônio do ser humano, enquanto parte integrante desta natureza. É neste sentido que a Educação Ambiental se torna necessária.

O papel dos museus e acervos educacionais consiste, em grande parte, na realização da comunicação das informações existentes em suas coleções através de exposições e atividades educacionais. Para que isso ocorra a contento, o museu ou acervo deverá adequar sua coleção para torná-la acessível ao trabalho educativo que se pretende alcançar. Deste modo, a linguagem e forma de apresentação do material que compõem a coleção aberta à visitação devem levar em consideração a faixa etária e os ciclos de aprendizagem da clientela visitante.

Durante as visitas de grupos escolares, o professor responsável por acompanhar os estudantes ao museu ou acervo deve se inteirar das coleções e das atividades propostas com antecedência, para que seja possível o trabalho dos conteúdos previamente no ambiente escolar. Este procedimento facilita o entendimento dos visitantes e torna claro o real propósito da atividade. Também é importante a realização da avaliação da visita, tanto por parte do museu quanto por

\footnotetext{
${ }^{3}$ Matéria disponível em: http://epocanegocios.globo.com/Informacao/Dilemas/noticia/2015/01/museunacional-o-mais-antigo-do-brasil-fecha-por-falta-de-dinheiro.html. Acesso em 24/05/2015.
} 
parte da escola. Esta deve ocorrer de maneira sistemática e deve ser funcional, com a coleta de dados que expressem o real papel e importância da atividade extraescolar.

\section{OBJETIVOS}

O presente trabalho buscou verificar as estratégias que uma universidade poderia estar promovendo para a constituição de um espaço visando ao desenvolvimento de práticas relacionadas à Educação Ambiental. Para tanto, foram utilizadas ações que integram diferentes agentes, tais como coordenações de Cursos, acadêmicos, funcionários, com o propósito de viabilizar a criação do Acervo Educacional de Ciências Naturais - AECIN.

\section{METODOLOGIA}

Inicialmente foram realizados estudos para a implantação do Acervo Educacional de Ciências Naturais da Universidade do Oeste Paulista, por meio de reuniões para captação da demanda existente no Curso de Ciências Biológicas e, posteriormente, envolvendo outros cursos nas áreas de Ciências Agrárias e Engenharias. Foi constatado que existia uma enorme carência de um espaço como este na universidade, o que motivou que esforços fossem empenhados para a constituição deste Acervo.

Para o desenvolvimento do projeto de criação do AECIN, utilizou-se a abordagem metodológica qualitativa como norteadora do levantamento de como a Educação Ambiental é realizada na esfera mundial e nacional. Em adição foi realizado um resgate documental e dos dados levantados que permitiram 0 entendimento quanto às estratégias de Educação Ambiental em museus e acervos de Ciências Naturais. 


\section{RESULTADOS}

\section{A experiência da Universidade do Oeste Paulista}

Pensando em proporcionar um espaço diferenciado para a realização de ações voltadas ao ensino, pesquisa e extensão em Ciências Naturais, bem como atender à uma demanda latente apresentada inicialmente nos cursos de Ciências Biológicas e, posteriormente, nos cursos de Ciências Agrárias e Engenharias e, em seguida, pela Rede Pública e Particular de Educação Básica do município de Presidente Prudente (SP) e, inclusive, a nível regional, a administração central da Universidade do Oeste Paulista - UNOESTE, através da sua Pró-Reitoria de Extensão e Ação Comunitária - PROEXT, promoveu a institucionalização do Acervo Educacional de Ciências Naturais - AECIN.

Instituído em maio de 2008, como um ambiente interdisciplinar favorável ao desenvolvimento de atividades científicas, educativas, culturais e de extensão à comunidade da região Oeste Paulista, o AECIN possui como missão preservar o patrimônio natural e ainda promover $\mathrm{o}$ interesse dos visitantes pelas Ciências Naturais, por meio de exposições, educação e incentivo à pesquisa.

São objetivos do AECIN organizar coleções didáticas e científicas no âmbito das Ciências Biológicas, das Geociências e áreas correlatas. Deste modo, neste espaço da UNOESTE são elaboradas e promovidas atividades educativas e estimulado o desenvolvimento de pesquisas científicas na área ambiental, propiciando um ambiente adequado, de modo a contribuir para a melhoria da qualidade do ensino de Ciências Naturais nos cursos da Educação Básica (Ensinos Fundamental e Médio), Graduação e Pós-graduação do município e da região.

O corpo gestor do AECIN é formado pela Pró-Reitoria de Extensão e Ação Comunitária e Coordenações dos Cursos das áreas afins (Ciências Biológicas modalidades Licenciatura e Bacharelado; e Medicina Veterinária). A coleção permanente do $A E C I N$ encontra-se aberta à visitação pública, mediante agendamento junto a PROEXT. O registro dos visitantes é realizado sistematicamente, assim como a aplicação de questionários de avaliação das atividades oferecidas.

Atualmente, o AECIN é composto por dezoito seções/coleções em exposição permanente; uma coleção itinerante, destinada a visitas a escolas públicas e 
particulares; uma coleção reserva, destinada a substituição de peças danificadas da exposição permanente; uma coleção didática, destinada a alunos portadores de deficiência física, principalmente visual, que necessitam tocar as peças; e uma coleção para uso em laboratório. No início do ano de 2015, apenas as peças pertencentes às coleções permanente e itinerante do departamento totalizavam 5.502 amostras/peças à disposição de visitantes e demais usuários.

A incorporação de novas peças que compõem as coleções do AECIN é realizada observando-se normativas do Instituto Brasileiro de Museus (IBRAM) e do Instituto Brasileiro do Meio Ambiente e dos Recursos Naturais Renováveis (IBAMA). Os empréstimos de materiais e as exposições itinerantes são solicitadas por escolas, parques zoológicos, institutos de pesquisas, shoppings centers, centros culturais e outros, por meio de ofício documentado.

O AECIN desenvolve trabalhos com o auxílio de alunos de graduação e pósgraduação, na qualidade de monitores, com o objetivo de capacitar o acadêmico para a licenciatura e a pesquisa, além de propiciar o oferecimento de monitorias em visitas agendadas, pesquisas para realização de exposições temáticas e monitorias em exposições itinerantes, capacitação para preparação de peças e participação em organização de eventos promovidos pelo departamento.

Há também, a possibilidade de desenvolvimento de Estágio Curricular Supervisionado, Projetos de Iniciação Científica (e outras pesquisas científicas), Trabalhos de Conclusão de Cursos (Graduação e Pós-Graduação). A seleção de acadêmicos monitores é realizada levando-se em consideração o bom desempenho nas disciplinas curriculares nos cursos em que estão matriculados.

Por meio das visitas monitoradas agendadas, o AECIN atende a comunidade estudantil de Presidente Prudente (SP) e região, em atividades destinadas à conscientização da preservação dos recursos naturais. As visitas monitoradas têm duração média de 2 horas e seguem um roteiro preestabelecido, com a ministração de palestra voltada à educação ambiental (ou específica de uma das áreas do conhecimento propostas pelo AECIN), seguida de visita à coleção permanente. As palestras podem ser ministradas por professores convidados ou pelos próprios acadêmicos formandos, que se propuserem a prepará-las.

A implantação do AECIN e as ações desenvolvidas neste departamento 
tornam clara a possibilidade de envolvimento da universidade na contribuição para o exercício da Educação Ambiental em todos os níveis educacionais, conforme previsto na Lei Lei $n^{\circ} 6.938$, de 31/08/81, anteriormente mencionada. Pelas suas características e atividades educacionais desenvolvidas, pode-se afirmar que o AECIN contribui com a formação de cidadãos preocupados com a questão ambiental.

\section{CONCLUSÃO}

Os museus e acervos educacionais caracterizam-se por promover a compreensão pública das Ciências através de experiências educativas informais ou não formais, e proporcionar a assimilação de informações científicas de forma agradável e em um ambiente diferenciado de ensino. A visita a um museu e o contato com as coleções disponibilizadas por um acervo educacional podem proporcionar o entendimento de questões discutidas em ambientes formais de ensino, promovendo reflexões por vezes inconcebíveis por meio de aulas expositivas ministradas no interior das escolas.

A aprendizagem pode ocorrer através do envolvimento do público visitante em atividades de aprendizagem relacionadas ao acervo do Museu, dentro ou fora do mesmo. Desta forma, os museus e acervos educacionais, além de armazenar fontes de informação também possibilitam a interação do visitante com os objetos expostos, contribuindo com o processo de aprendizagem ao oferecer novas opções de ensino.

As características didáticas e educacionais do Acervo Educacional de Ciências Naturais - AECIN, as atividades extracurriculares propostas, bem como a disposição e apresentação de suas coleções permitem concluir que o mesmo preocupa-se com a instrução de seu público visitante, utilizando-se de suas coleções e da dinâmica de recepção a este público, permitindo a transformação do trabalho educacional num complemento escolar especializado em ambiente acadêmico. 


\section{REFERÊNCIAS}

AGENDA 21 Global. [Brasília]: Ministério do Meio Ambiente. Disponível em: http://www.mma.gov.br/responsabilidade-socioambiental/agenda-21/agenda-21-global. Acesso em: 31 maio 2015.

BRASIL. Presidência da República. Casa Civil. Subchefia para Assuntos Jurídicos. Lei no 6.938, de 31 de agosto de 1981. Dispõe sobre a Política Nacional do Meio Ambiente, seus fins e mecanismos de formulação e aplicação, e dá outras providências. Disponível em:

<http://www.planalto.gov.br/ccivil_03/leis/16938.htm>. Acesso em: 09/07/2013.

CADERNOS de Sustentabilidade da Rio+20: diretrizes de sustentabilidade e guia de boas práticas da organização da conferência das nações unidas sobre desenvolvimento sustentável. Brasília: Fundação Alexandre de Gusmão, 2012. 206 p. Disponível em: http://www.rio20.gov.br/documentos/omodelo-brasileiro-e-cardernos-da-sustentabilidade-da-rio-20/1.-caderno-

sustentabilidade/at_download/caderno_sustentabilidade_rio20.pdf. Acesso em: 24 maio 2015.

CARTA de Belgrado: uma estrutura global para a educação ambiental. [Brasília]: Ministério do Meio Ambiente. Disponível em: http://www.mma.gov.br/port/sdi/ea/deds/pdfs/crt_belgrado.pdf. Acesso em: 31 maio 2015.

COMISSÃO MUNDIAL SOBRE MEIO AMBIENTE E DESENVOLVIMENTO. Nosso Futuro Comum. Rio de Janeiro: FGV, 1991.

CORTELLA, Mário Sérgio; BARROS FILHO, Clóvis de. Ética e vergonha na cara! Campinas: Papirus, 2014, p. 46 - Col. Papirus Debates.

DECLARAÇÃO de Estocolmo sobre o ambiente humano - 1972. São Paulo: Universidade de São Paulo, Biblioteca Virtual de Direitos Humanos. Disponível em: http://www.direitoshumanos.usp.br/index.php/Meio-Ambiente/declaracao-de-estocolmo-sobre-oambiente-humano.html. Acesso em: 31 maio 2015.

DECLARAÇÃO de Johanesburgo sobre Desenvolvimento Sustentável. [Brasília]: Ministério do Meio Ambiente. 6 p. Disponível em:

http://www.mma.gov.br/estruturas/agenda21/_arquivos/joanesburgo.doc. Acesso em: 31/05/2015.

DECLARAÇÃO de Tbilisi. [Brasília]: Ministério do Meio Ambiente. Disponível em:

http://www.mma.gov.br/port/sdi/ea/deds/pdfs/decltbilisi.pdf. Acesso em: 31 maio 2015.

DECLARAÇÃO de Thessaloniki. São Paulo: Sistema Ambiental Paulista. Disponível em: http://www.ambiente.sp.gov.br/wp-content/uploads/cea/Decl.Thessaloniki.pdf. Acesso em: 24 maio 2015.

MEADOWS, Dennis L.; MEADOWS, Donella; RANDERS, Jorgen. Limites do Crescimento. Rio de Janeiro: Qualitymark, 2007.

MUSEU Nacional, o mais antigo do Brasil, fecha por falta de dinheiro: especializado em história natural, ele é o maior dessa área na América Latina. Época Negócios, 12 jan., 2015. Disponível em: http://epocanegocios.globo.com/Informacao/Dilemas/noticia/2015/01/museu-nacional-o-mais-antigodo-brasil-fecha-por-falta-de-dinheiro.html. Acesso em: 24 maio 2015.

RELATÓRIO Rio+20: o modelo brasileiro: relatório de sustentabilidade da organização da Conferência das Nações Unidas sobre Desenvolvimento Sustentável. Brasília: Fundação Alexandre de Gusmão, 2012. 143 p. Disponível em:

http://www.mma.gov.br/images/noticias_arquivos/pdf/dezembro_2012/relatorio-rio20_atual.pdf. Acesso em: 24 maio 2015.

SANTOS, Maria Célia T. Moura. Museus Universitários Brasileiros: novas perspectivas. In: VI Encontro do Fórum Permanente de Museus Universitários e II Simpósio de Museologia da 
UFMG. "Museus Universitários - Ciência, Cultura e Promoção Social", Belo Horizonte - MG, 24 a 28 de agosto de 2006.

UNIVERSIDADE DO OESTE PAULISTA. Acervo Educacional de Ciências Naturais. Regulamento Geral. Presidente Prudente: AECIN, 2013.

WALDMAN, Maurício. COIMBRA, José de Ávila Aguiar (coord.). Meio ambiente \& antropologia. São Paulo: Editora SENAC, 2006. (Série Meio Ambiente, 6). 